\title{
UMBRALES DE DISRUPCIÓN: NOTAS INICIALES PARA UNA GENEALOGÍA DE LAS INTERVENCIONES CRÍTICAS Y DIDÁCTICAS SOBRE LITERATURA Y PERSPECTIVAS SEXOGENÉRICAS
}

\author{
Roberto A. Breganni \\ Universidad Autónoma de Entre Ríos \\ roberto_breganni@yahoo.com.ar
}

Resumen: El presente artículo traza una genealogía inicial acerca de las intervenciones críticas y didácticas elaboradas desde los vínculos entre literatura y perspectivas sexogenéricas, en el marco del proceso de institucionalización de estos estudios en las carreras docentes de Letras de la universidad argentina. En este sentido, revisa intervenciones críticas de Nicolás Rosa, Jorge Panesi y Josefina Ludmer poniéndolas en diálogo con categorías, propuestas e hipótesis de trabajo presentes en sus programas de cátedra y seminarios de grado. Las consideraciones vertidas sugieren $-\mathrm{a}$ modo de esbozo preliminar- una posible mirada introductoria y conceptualizaciones construidas con el objeto de describir y explicar las reflexiones desarrolladas en el recorrido planteado.

Palabras clave: Literatura, Perspectivas sexogenéricas, Intervenciones críticas y didácticas, Genealogías, Institucionalización.

\begin{abstract}
This article traces an initial genealogy of the critical and didactic interventions elaborated from the links between literature and sex-generic perspectives, within the framework of the institutionalization process of these studies in language and literature teaching degrees of the Argentinean university. In this sense, the material to be worked with are the critical interventions of Nicolás Rosa, Jorge Panesi and Josefina Ludmer, which are in dialogue with categories, proposals and working hypotheses that are exposed in their academic programs and seminars. These considerations suggest -as a preliminar sketch- a posible introduction to conceptualizations constructed in order to describe and explain the reflections developed in the current work.
\end{abstract}

Keywords: Literature, Sex-generic perspectives, Critical and didactic interventions, Genealogies, Institutionalization. 


\section{Notas preliminares}

En este artículo nos proponemos trazar una genealogía inicial sobre las intervenciones críticas y didácticas concebidas alrededor de las perspectivas sexo-genéricas en relación con la literatura (Gasparri, 2015, 2016; Saxe, 2018, 2020), en el marco de una reconstrucción de su proceso de institucionalización (Blanco, 2006; Gerbaudo, 2016) en las carreras de Profesorado en Letras. ${ }^{1}$ Particularmente, nos enfocaremos en un corpus documental perteneciente a tres críticos-docentes de la Universidad de Buenos Aires, agentes ampliamente reconocidos en el campo. El análisis se orienta hacia el impacto de dichas perspectivas en las elaboraciones de los programas de cátedra ligados o relacionados con los estudios literarios, con el objetivo de conocer cómo comenzaron a institucionalizarse los estudios de sexualidades y género para, a partir de allí, explorar los efectos críticos que tiene esto en la literatura y en los matices e inflexiones que se proyectan sobre las prácticas de enseñanza de la literatura.

Primeramente, cabe señalar que, en su proceso de institucionalización, los estudios de perspectiva sexogenérica fueron transitando una evolución epistemológica versátil. Su génesis puede inscribirse en las áreas de estudios sobre la mujer que, posteriormente, se convirtieron en estudios de género,

\footnotetext{
${ }^{1}$ La investigación mayor en la que se inscribe este trabajo plantea un recorrido por cuatro universidades nacionales argentinas durante el periodo comprendido entre 1984 y 2003: la Universidad de Buenos Aires, la Universidad Nacional de la Plata, la Universidad Nacional de Rosario y la Universidad Nacional de La Pampa. Las tres primeras porque marcan el "campo" (Bourdieu, 1999) y la última, porque en ella se encuentra un agente clave en su configuración: José Maristany.
} 
desde un espacio de abordaje interdisciplinario. Luego, también, a estas líneas se le adhieren los desarrollos analíticos acerca de las sexualidades, que provenían principalmente desde los estudios gay-lésbiscos, antes de arribar a lo queer. De este modo, todas estas epistemologías de proveniencia un tanto heterodoxas fundan la matriz genealógica de lo sexogenérico.

El entramado teórico desde el cual abordamos estos vínculos parte del concepto de "institucionalización". En este sentido, Alejandro Blanco (2006) sostiene que una disciplina se institucionaliza cuando se instaura como un "tema mayor", lo que implica el cumplimiento de ciertas características ineludibles: a) es enseñada por especialistas; b) requiere el despliegue de una serie de prácticas ligadas a la producción de conocimiento; c) obtiene financiamiento de instituciones establecidas a tal fin para satisfacer la demanda de los resultados de la investigación. Además, Analía Gerbaudo (2016) agrega que las condiciones antes descriptas deben darse en simultaneidad, atendiendo los índices que marcan esa institucionalización: enseñanza, investigación, publicaciones y organización profesional.

En tanto para la categoría de "sexogenérico", tomamos la definición que propone Javier Gasparri (2016), quien afirma que esta perspectiva se plantea como un conjunto de:

formulaciones críticas con diferentes modulaciones y puntos de vista, es decir, con configuraciones conceptuales que abrevan en diferentes teorías, tradiciones filosóficas y disciplinas [...] [que] se agrupan como "sexogenéricas" ya que la cuestión sexo/género posee inflexiones históricas en su propio devenir conceptual así como distintos enfoques epistemológicos [...] [y se ubican] en disidencia respecto del falogocentrismo, la heterosexualidad obligatoria y normativa, 
el heteropatriarcado hegemónico, y se proponen desmontarlos, subvertirlos, etc. (Gasparri, 2016, p. 176).

Entonces, las perspectivas sexogenéricas se fundan desde este entramado de préstamos, tensiones, articulaciones y fronteras borrosas en el que conviven y se intersectan. En esta línea se inscribe la conceptualización que propone Facundo Saxe (2020), que la piensa como "una categoría/posibilidad/noción fluida, en disputa, contradicción y constante movimiento, asociada más a una idea de versión [...] [y construida] alrededor de una constelación de apariciones y retroalimentaciones, más que en una definición cerrada" (2020, p. 3). Estos cruces y tensiones que convergen en un desplazamiento dinámico confluyen en un territorio cuya filiación se vuelve dificultosa de determinar, pero que, de todos modos sí se identifican y hermanan en un sentido: lo sexogenérico invoca el poder de la literatura para mirar la disidencia y dar lugar a conjeturas que hacen crujir la heteronorma cultural.

Desde este marco, consideramos que, en su desarrollo, los estudios sobre sexualidades y género como así también los estudios queer, fueron configurando la matriz genealógica de las perspectivas sexogenéricas; y que esos rastros o insinuaciones hallaron un área fecunda en el campo de las Letras, impactando más específicamente en derivas formuladas en Teoría y Crítica Literaria y en Literatura Argentina. En esta línea y para conocer su evolución, resultan relevantes las elaboraciones que propone Eduardo Mattio (2012), quien describe, desarrolla y sistematiza las tensiones, corrimientos y disputas de los conceptos de sexo y género a lo largo del tiempo, piezas necesarias para entender los aspectos fundamentales de la teoría queer que explica David 
Córdoba (2007). Este panorama inicial que describen los autores permite comenzar a pensar la red de préstamos y articulaciones en que se fundan las perspectivas sexogenéricas y su vigor para observar y plantear conjeturas que discuten la heteronorma cultural en el campo de la literatura.

A partir de estas consideraciones, examinaremos algunas de las intervenciones críticas de Nicolás Rosa, Jorge Panesi y Josefina Ludmer poniéndolas en diálogo con categorías, propuestas e hipótesis de trabajo presentes en sus programas de distintos seminarios y cátedras en la Universidad de Buenos Aires. El propósito de este procedimiento es rastrear, en los cruces entre la experiencia áulica y su producción crítica, conexiones que admitan un vínculo con alguna tentativa o vislumbre de perspectivas sexogenéricas en el campo de la literatura y los estudios literarios.

Por otro lado, para poder responder a las demandas metodológicas y analíticas del trabajo, construimos dos categorías que consideramos clave para explicar estas aproximaciones iniciales: "archivo sampleado operacional" y "umbrales de disrupción". 2

\section{Archivo sampleado operacional}

\footnotetext{
${ }^{2}$ Ambas categorías se encuentran en una instancia incipiente de construcción.
} 
Para componer una cartografía que congregue y sistematice las actividades y procedimientos que se inscriben en esta línea, es necesario rastrear programas de cátedra y publicaciones que revelen o insinúen propuestas de abordaje de la literatura desde perspectivas sexogenéricas -o marcados por ellas-durante el periodo 1984-2003 en las universidades mencionadas. Se trata de una tarea para nada sencilla y de resultado incierto hasta el momento, en virtud de que no existe una fuente de conservación y/o registro concreta y precisa a la cual recurrir para recuperar todos esos documentos. Esta circunstancia se debe en parte a que, como sostiene Juan José Mendoza (2019), Argentina adolece de cierta "desidia archivística", ya que nos falta una "conciencia documental". En este punto, advertimos la necesidad de conformar un archivo documental que reúna estos materiales, en concordancia con lo que sostiene Pampa Arán, desde premisas que recuperan una lectura derrideana sobre el tema:

Cabe recordar que la finalidad del archivo es "consignar", reunir los signos en un solo corpus, como señala Derrida (1997, p. 11) y deja de ser solo un conjunto documental almacenado, para responder a un principio organizador, a una ley. Esta forma de organización (selección, clasificación, repetición, denominación, exhibición) ya es un modo de lectura e interpretación (2018, p. 87).

Así, esta reunión de diferentes textos aguarda abierta a una nueva interpretación que recupere su(s) sentido(s) y que contribuya a rescatar $y$ discutir otros que pueden, potencialmente, desplegarse. Un punto de partida que, a través 
de otros procedimientos o transferencias, podría permitir desarrollos ulteriores en escenarios futuros. Parafraseando a Hal Foster (2017), una promesa de revelación, desde el buceo entre avisos enigmáticos o vestigios desconocidos del pasado.

Por lo expuesto, detectamos la necesidad de crear un archivo documental que reúna los materiales exactos que la investigación demanda (Foster, 2017), e insistimos con la cualidad de exacto debido a un principio de evasión que se halla presente en todos los archivos y que explica Miguel Dalmaroni:

el imperativo totalista del archivo (guardarlo todo) corroe sus posibilidades de totalización: restará siempre algo fuera de orden, aleatorio, heterogéneo; se irán dibujando en las extravagancias de sus usos senderos y consignaciones no previstas. Una ley no escrita del archivo dice que a mayor almacenamiento, a mayor capacidad de acopio, las posibilidades de fuga de sentido, lejos de reducirse, se multiplican. (2010, pp. 25-26).

Desde estas consideraciones, advirtiendo la necesidad de acuñar parte de los materiales que constituirán el corpus del derrotero metodológico, construimos nuestra propia categoría de "archivo", acorde a las demandas y alcances del trabajo que trazamos. Así surge el concepto de "archivo sampleado operacional".

Con este término hacemos referencia al archivo constituido con muestras documentales sobre un tema o problema, que representa un fragmento significativo del archivo total posible, $y$ que permite operar de manera eficaz en las tareas de interpretación que le otorguen sentido. Tomo el término en préstamo del campo de la música, en el cual el anglicismo 
sampleado hace referencia al acto de tomar una porción o muestra (sample) de un sonido grabado en cualquier tipo de soporte para reutilizar posteriormente como un instrumento musical o una tonalidad diferente para producir una composición musical. ${ }^{3}$

Esta deriva del concepto de archivo admite la posibilidad de trabajar con un corpus preciso de materiales que, como afirma Dalmaroni, reducirá la fuga de percepciones, al tiempo que permitirá elaborar significados y consideraciones relevantes en el marco de nuestra indagación.

Asimismo, las conceptualizaciones de Michael Foucault (1970) sobre la noción de archivo revelan aspectos que sustentan la construcción categorial ya que, como sostiene, el archivo no se constituye por una acumulación de documentos, sino por el sistema de enunciados en el que se diferencian regiones heterogéneas, pero que se agrupan, componen y mantienen según relaciones múltiples de regularidad y que permite establecer el sistema de formación y transformación de lo que puede ser dicho.

De este modo, para esta constitución preliminar del archivo sampleado recuperaremos los siguientes materiales: programas de Cátedra y de un Seminario de grado, artículos publicados en revistas académicas y un ensayo editado en Puerto Rico en un volumen que reunió una serie de conferencias brindadas en el "Encuentro de escritoras latinoamericanas" desarrollado en dicho país.

\footnotetext{
3 Según manifiesta Juan José Mendoza (2019), de algún modo, todos los investigadores somos operadores de archivo que "sampleamos" fragmentos del pasado.
} 
Así, para analizar las intervenciones de Nicolás Rosa, nos enfocamos en el programa del Seminario "Análisis textual de El entenado de J.J. Saer" dictado en la Universidad de Buenos Aires por el mencionado profesor en el segundo cuatrimestre del año 1985 y el Programa de la cátedra "Teoría Literaria III" correspondiente al año académico 1990. También en los artículos "CUERPO/ CUERPOS. Hacia una gramática social de los cuerpos" (1999), publicado en la Revista de Letras, editada por la Facultad de Humanidades y Artes de la Universidad Nacional de Rosario y "De monstruos y pasiones" (2002), publicado en la Revista Materia, editada por la Universitat de Barcelona.

Luego, en el abordaje de los desarrollos de Jorge Panesi, tomamos el Programa de la cátedra "Teoría y Análisis Literario - C", correspondiente al primer cuatrimestre del año 1993 y el artículo "Marginales en la noche" (1998), publicado en BOLETÍN, revista del Centro de Estudios de Teoría y Crítica Literaria de la Facultad de Humanidades y Artes de la Universidad Nacional de Rosario.

Finalmente, para examinar las propuestas de Josefina Ludmer, nos detendremos en el Programa de la cátedra "Teoría Literaria II", correspondiente al primer cuatrimestre de 1992 y al ensayo "Las tretas del débil" (1985), editado en el libro La sartén por el mango. Encuentro de escritoras latinoamericanas, volumen que reúne los trabajos del encuentro.

Frente a estos documentos, la propuesta es una aproximación que pretende relevar autores, textos y categorías teóricas que conforman una zona de entramados transdisciplinares y que, según entendemos, permiten vislumbrar algunas de las 
operaciones anunciadas previamente en los objetivos de este trabajo. En este sentido, la identificación de esas huellas resulta relevante, ya que nos permite incorporar datos reveladores para configurar el proceso de institucionalización sobre el que nos interesa indagar.

\section{Rosa, Panesi, Ludmer: Literatura y perspectivas sexogenéricas}

La década del noventa se caracteriza por "la consolidación del campo de producción nacional, a través de la inclusión de lecturas de un conjunto de teóricos y críticos argentinos" (Lacalle y Bogado, 2017, p. 1). En este apartado, nos enfocaremos en quienes se establecieron como agentes centrales del campo nacional: Nicolás Rosa, Jorge Panesi y Josefina Ludmer, "nombres propios que nos permiten ubicarnos dentro de una tradición en la teoría literaria argentina" (Lacalle y Bogado, 2017, p. 9) y, lo que es más significativo, con una marcada predilección hacia el corpus de objeto literario argentino y latinoamericano.

Rosa, Panesi, Ludmer. Tres nombres propios, tres estilos diferentes, pero con un común denominador: el lugar otorgado a las operaciones teóricas, críticas y pedagógicas; el modo de entender la actividad crítica en estrecho vínculo con una lógica didáctica (Lacalle y Bogado, 2017; Gerbaudo, 2016).

\section{Rosa: literatura y sexualidad}


Crítico literario y docente, el nombre de Nicolás Rosa se asocia ineludiblemente con un modo, un estilo de entender la actividad crítica y, además, por "la estrecha ligazón de esa performática con una lógica didáctica" (Lacalle y Bogado, 2017, p. 10). Proveniente de Rosario, incursionó por primera vez en la carrera de Letras de la Universidad de Buenos Aires en 1985 dictando el Seminario "Análisis textual de El entenado de J.J. Saer" para, posterior y definitivamente, convertirse en 1989 en el primer docente de la flamante cátedra "Teoría Literaria III".

Rosa fue un agente fundamental de la recepción del pensamiento crítico francés en Argentina. Su labor se expande hacia el ámbito de las ciencias humanas, con una progresiva centralidad hacia el psicoanálisis y la filosofía a partir de autores como Foucault, Lacan, Bataille y Derrida. En ese devenir, su proyecto crítico le fue otorgando un lugar cada vez más importante a "la reflexión sobre el sujeto basada en los aportes del psicoanálisis" (Hidalgo Nácher, 2017, p. 57).

Siempre tuvo especial curiosidad por los textos de Sade, acaso guiado por las ideas de algunos de los filósofos franceses que frecuentaba. En sus intervenciones críticas se ocupó no solamente de revisar la producción estrictamente literaria del Marqués, sino también de sus cartas y memorias. Sobre estos últimos géneros -y en particular el epistolar-, amparado en las sentencias de Lacan y Freud y bajo el halo del discurso de la psiquiatría clásica y el psicoanálisis, Rosa describía que las memorias y las cartas son géneros que "organizan el discurso psicótico" (1990, p. 23) en la literatura, porque manifiestan el 
campo de la intersubjetividad, del ego, algo que entendía era característico de la obra de Sade.

Más tarde, en el artículo titulado "Cárcel de amor" (1994), publicado en el número tres de la Revista de Letras, profundizaba esa perspectiva y escribía que las cartas del Marqués de Sade son formas de demandas en el sentido psicoanalítico que proclamaban la circulación y el furor liberticida de los cuerpos. En esta oportunidad, los filósofos que conforman su plataforma teórica eran Jacques Derrida, Jean-Jacques Rousseau y Soren Kierkegaard. Los textos citados de estos pensadores son aquellos que abordan, remiten o se enmarcan en el género epistolar: $L a$ tarjeta postal (Derrida), Julia o la nueva Eloísa. (cartas de dos amantes) (Rousseau) y Cartas del noviazgo (Kierkegaard).

En el artículo "De monstruos y pasiones" (2002) Rosa se explaya aún más en la cartografía que traza sobre el Marqués de Sade. En él, posicionado en un triángulo disciplinar compuesto por la sociología, la antropología y la psiquiatría, sostiene que el texto sadiano se convierte en una multitud de textos posibles, atravesado por lo psicoanalítico, lo sociológico y hasta lo pornográfico.

Tras una serie de formulaciones analíticas en las que dialogan Barthes, Lacan y Engels -entre otros-, va tejiendo una madeja de consideraciones en las que destaca que las ficciones de Sade son autobiográficas, pues están determinadas por la existencia de sus fantasmas eróticos y, en su interior, se libra un combate entre la intención literaria y una sexualidad aberrante, en el cual justamente lo aberrante, lo monstruoso, resulta natural. El lector 
de Sade, concluye, "queda reducido al papel de espectador de la dramaturgia sexual sadiana" (Rosa, 2002, p. 217).

Por otro lado, en sus propuestas permanentemente busca situar el discurso de la crítica en relación con la historia. Alude a esta disciplina como "uno de los discursos teóricos (junto con la retórica, la filosofía y la psicología) cuyas categorías, tamizadas por la operación crítica, permiten construir los objetos de estudio de los estudios literarios." (Lacalle y Bogado, 2017, p. 4).

Desde este marco, en sus programas de clases se leen hipótesis de trabajo que se encuentran ligadas y que se mantendrán en el tiempo, a partir de lo cual se vislumbra un entramado transdisciplinar que guía su pensamiento y su forma de entender la literatura y la crítica. Así lo enuncia en el primer programa de “Teoría Literaria III" (1989) y y lo replica en el de 1990:

- Enfrentar al alumno con la problemática crítica contemporánea en un nivel de generalidad mayor que aquel que abarca la teoría y la crítica literarias en el sentido estricto.

- Situar dentro de esa problemática abarcadora los saberes contemporáneos que determinan y condicionan el saber literario (saber de la literatura y saber sobre lo literario) y aquellos que a veces colisionan y limitan sus fronteras.

De este modo, se observa enunciada una voluntad de traspasar las fronteras de las disciplinas literarias desde un entrecruzamiento teorético proveniente de diversos campos, que excede lo estrictamente literario. Al año siguiente, en el Programa de "Teoría Literaria III" (1990), suma a estas dos

\footnotetext{
${ }^{4}$ Cfr. Programa de cátedra “Teoría Literaria III” (2 cuatrimestre 1989). Departamento de Letras. FFyL-UBA.
} 
hipótesis una tercera, que se centra en el problema de los discursos de la sexualidad, el amor y el erotismo, con el énfasis puesto en la literatura argentina que presenta esta problemática (Lacalle y Bogado, 2017).

Entablando un diálogo entre la labor crítica y la didáctica, en el artículo "CUERPO/ CUERPOS. Hacia una gramática social de los cuerpos" (1999) recupera y conjuga aquella tercera hipótesis de trabajo con la idea plasmada en el programa del seminario dictado en 1985, "Análisis textual de El entenado de J.J. Saer" en el cual pone en juego y articula en el texto de Saer el ritual orgiástico-antropofágico de los indios colastinés y la noción de orgía sadiana en una composición que invoca, en la representación literaria, el poder, la sexualidad y el erotismo bajo la lupa examinadora de la historia, la antropología y el psicoanálisis.

En ese documento, dentro del Eje denominado "Cómo se hace la historia (o un tratado de antropología fantástica)", Rosa propone abordar el tema de la antropofagia ritual a través de un desagregado que se plantea hacia tres posibilidades: cómo se construye una orgía clásica, cómo se construye una orgía americana y cómo se construye una orgía sadiana. Esta última es sobre la que nos interesa orientar nuestra mirada.

A partir de lo expuesto, para pensar las articulaciones que mencionamos, debemos reponer sintéticamente el fragmento del argumento de la novela donde se posa el cenital de la categoría en cuestión.

En la obra se narran las peripecias de una expedición española por el Río de la Plata capturada por una tribu de indios 
antropófagos. Los indios matan a todos, salvo al grumete, a quien mantienen con vida en su poblado durante diez años. El entenado (hijastro) es el grumete que es "adoptado" por los indígenas. Pero mientras permanece con ellos lo hará sin participar en la vida de la tribu salvo como un espectador al que, además, nadie le explica nada. De este modo, el joven presenciará cómo los indios asan a sus compañeros de barco y los devoran en un ritual festivo que termina de una manera orgiástica, cuando todos sucumben a una especie de delirio colectivo en el que se entregan a la comida y al sexo hasta que, transcurrido un tiempo, su ánimo se aplaca y se calman como si nada de lo anterior hubiese sucedido.

La escena de la orgía en la novela describe una resurgencia de un estado primitivo, de lo arcaico, a partir del cual, dominados por una fuerza oscura y ancestral, los indios colastinés se ven arrastrados periódicamente a sus banquetes antropofágicos y orgías incestuosas (Bermúdez Martínez, 2001).

Desde esta contextualización, proseguimos con la definición de orgía. Para Lucienne Frappier-Mazur, la "orgía" se define como "la representación de una acción colectiva centrada en el exceso sexual, alimenticio" (Frappier-Mazur, 2006, p. 3). En el artículo -en el que se entrecruzan y dialogan Bataille, Lacan, Freud y Berger- Rosa explica que la comida -como el poderson formas de devoración del mundo. La comida remite a impulsos primarios, remite retóricamente al festín y un festín de comida es una orgía. Además, sostendrá que la apropiación de la sustancia corporal como demostración de poder se da desde las dos dimensiones de la orgía: por un lado, por la ingestión 
carnívora del acto antropofágico y, por otro, por la sensación poscoital de posesión producida tras el acto sexual.

De este modo, recurre al tema de la orgía como punto para atravesar el problema de los discursos de la sexualidad y el erotismo en la literatura argentina desde la retórica sadiana, la que consideraba, siguiendo a Barthes, una retórica de lo erótico (Rosa, 1994).

Así, a partir de estos envíos y derivas se pueden rastrear algunas tensiones y conexiones entre orgía sadiana y perspectivas sexogenéricas. Entonces, si bien la representación del libertinaje sexual sadiano para varios autores ofrece una continuidad con la lógica de normalización patriarcal y de sometimiento de las mujeres, para otros representa una mirada opuesta. Por ello, sin desconocer los interrogantes e interpelaciones que las tensionan desde términos enfrentados, recuperamos algunas de estas consideraciones para enfocar desde un ángulo más preciso la hipótesis inicial.

Desde este marco, Natalia Zorrilla Sirlín sostiene que el libertinaje sexual que caracteriza a las novelas sadeanas:

se concibe a sí mismo y se construye, dentro de la diégesis de la escritura ficcional y de la articulación del pensamiento filosófico expresado por los personajes libertinos, como una fuerza de choque contra el sistema de valores, instituciones y prácticas basadas en la idea de una sexualidad puramente reproductiva y hetero-normativa (2016, p. 92).

En esta línea, desde la invocación del carácter simbólico de la orgía sadiana, en el libro "Sade y la escritura de la orgía" (2006), Lucienne Frappier-Mazur afirma que la orgía sadiana, simbólicamente, representa ruptura de los límites, abolición de 
las fronteras, transgresión del orden natural. Y enfatiza: "al interior de este simbolismo todas las diferencias se manifiestan por el quiebre de la diferencia sexual y se resuelven en su supresión. Sade busca abolir las diferencias ahogándolas en la indistinción heterogénea" (2006, p. 17).

Si bien el modelo de erotismo que se impone en las orgías sadianas implica una asimetría entre el objeto de goce y el sujeto deseante, esta diferencia no está necesariamente anclada al sexo o al género de los personajes. Es decir, el varón no es necesariamente el sujeto-dominante y la mujer objeto-dominada, sino que se desentiende de la idea de las identidades sexuales concebidas como esencias, por lo que la tesis de voluntad de dominio tiene alcance universal al aplicar teóricamente a todos los sujetos, independientemente de su sexo o género (Zorrilla Sirlín, 2016).

Pensada de esta manera, a partir de la cual se instaura una singular configuración del sistema sexo/género (Rubin, 1986), en la orgía sadiana se borra el sentido de la subalternidad (Spivak, 1998; Maristany, 2016), ya que los sujetos, hombre y mujeres, se igualan en los roles, dominios y atribuciones que ocupan en la dimensión natural del ritual (Buttler, 2014).

Estas reflexiones abonan el territorio que alberga los posibles aportes de los textos sadianos para pensar la equidad entre los individuos que revisten de distintas identidades de género. Acaso sean estas operaciones críticas de Nicolás Rosa que se enfocan en el concepto de "orgía sadiana", un germen conceptual que podría inscribirse en el campo transdisciplinar de los estudios feministas y sobre sexualidades y género. 


\section{Panesi: literatura y marginalidad}

Jorge Panesi se formó furtivamente con Josefina Ludmer durante los años del terrorismo de Estado en el mítico Seminario "Algunos problemas de teoría literaria", tránsito que dejó huellas en su desarrollo profesional (Cfr. Gerbaudo, 2016).

Formó parte del equipo de la cátedra "Introducción a la Literatura (C)", a cargo de Enrique Pezzoni. Tras el fallecimiento de este en 1989, quedó al frente de la asignatura. Sobre esta conexión, Analía Gerbaudo apunta: "Su imagen de crítico se construye entre el don y la deuda con Pezzoni” (2016, p. 258). Además de ser el profesor a cargo de la cátedra "C", fue durante varios periodos Director de la carrera de Letras. Sus clases exhiben cierta continuidad con el trabajo de Pezzoni con la incorporación, además, de los conceptos, enfoques e improntas propias de los aportes de los integrantes del equipo de cátedra (Cfr. Lacalle y Bogado, 2017).

Particularmente, nos interesa examinar el programa de 1993 que lleva como título "Crítica literaria, lectura y público". Si bien en este programa, "cultura" es reemplazado por el término clave "público", se sostiene un hilo conductor con el programa de 1990 -que inaugura su periodo a cargo de la cátedra- a través de las nociones de "cultura", "sentido e interpretación" y "género" (gender), nociones "que seguirán apareciendo y reapareciendo en los diversos programas a lo largo de toda la década" y cuya posición se centra en "los problemas de sentido y significación 
que se iluminan en función de sus contextos de aparición" (Lacalle y Bogado, 2017, pp. 12-13).

La unidad 5, denominada "Las concepciones de la lectura en la crítica contemporánea" es en la que se aborda el concepto de "género" (gender). En la parte (a) del eje "Las lecturas de las diferencias", los contenidos aparecen enunciados de esta manera: "La lectura del texto poético y el problema del género ("gender"): psicoanálisis, feminismo y teoría del sujeto" (Panesi, 1993 , p. 2). ${ }^{5}$

Específicamente, las semillas de esta propuesta teóricocrítico-didáctica se siembran cuando, en el marco de la enseñanza de la Teoría Literaria, el equipo docente comienza a pensar hacia fines de la década del ochenta, la inclusión de formulaciones teóricas relacionadas con perspectivas de género, feminismo y conceptualizaciones del cuerpo (Cfr. Maradei, 2020) hasta que finalmente emerge en la forma de este entramado de conceptos y problematizaciones, que hallan su enclave en la fundamentación y objetivos de la propuesta:

Este programa está articulado para revisar los conceptos a partir de los cuales la Teoría Literaria entra en correlación con los debates teóricos surgidos en las instituciones literarias tanto como en otros discursos y disciplinas [...].

[Se propone] comprender las bases teóricas de la discusión que dentro de la teoría literaria y en conexión con otras disciplinas se mantienen acerca de la fundamentación y legitimación de conocimientos en las ciencias sociales y humanísticas. [...].

\footnotetext{
${ }^{5}$ Participa la profesora Delfina Muschietti quien en sus clases pone en relación el concepto con el análisis de poesía a través de la lectura de Alfonsina Storni y Alejandra Pizarnik (Cfr. Lacalle y Bogado, 2017).
} 
[Se pretende] también [...] pensar las distintas maneras de leer, analizar y reflexionar la literatura, implícitas en la práctica crítica. (Panesi, 1993, pp. 2-3).

Se construye así una maquinaria donde interaccionan y se articulan los engranajes correspondientes a la teoría, a las operaciones críticas y a los dispositivos didácticos de transferencia a la enseñanza. Porque "lo que Panesi tiene para decir en torno a la teoría y la crítica se resuelve en el espacio áulico, en el cara a cara con los alumnos" (Lacalle y Bogado, 2017, p. 10).

Esta incursión inicial sobre los estudios de género marca la inauguración de las intervenciones de Jorge Panesi en un marco que podemos pensar ligado a lo queer, en tanto elaboraciones teóricas que discuten y proponen nuevas formulaciones en torno a las identidades y sexualidades disidentes. De este modo, comienza a vislumbrar el umbral de una crítica por venir, la que reafirma más adelante cuando escribe el artículo "Marginales en la noche" (1998) que recupera y pone en diálogo los aportes de Néstor Perlongher -inscriptos en su Tesis de Maestría O negócio do Michê-, sobre la prostitución masculina y la homosexualidad con la ficción literaria de "El juguete rabioso" de Roberto Arlt.

En este trabajo, Panesi expone que en la novela El juguete rabioso de Roberto Arlt, el encuentro del protagonista con el joven homosexual significa un encuentro y una ruptura. Un encuentro con otro, con otra posibilidad de sexo; y una ruptura con la ley, con lo moralmente admitido, con lo normativo.

Esta consideración elaborada a partir del despunte de una lectura (Gerbaudo, 2016) instala uno de los intersticios respecto 
de otras lecturas sobre la obra, más cercanas a "ficciones disciplinadoras" (Saxe, 2020) en la literatura, campo en el que siempre pugnan potentes y complejas relaciones y tensiones entre disidencias sexuales y "normalidad" heteronormativa.

En el ensayo, Panesi despliega una serie de argumentaciones a través de las cuales sostiene que en el texto literario de Arlt el deseo homosexual instala la ficción. Y que la ficción deja restos en la novela, en la literatura, a partir de los cuales se puede explorar la marginalidad. En este sentido, razona, en la prostitución masculina, el intercambio sexual y la retribución económica consecuente se instalan en una zona de ilegitimidad. Y lo ilegítimo solicita lo marginal. A pesar de que la retribución monetaria del placer sea un valor admitido en el funcionamiento social, ese contrato -que se ubica justamente al margen de la legalidad- resulta clave para transformarlo en un régimen de la marginalidad, aun siendo "alternativas controladas y controlables respecto de ese gran conjunto de la sexualidad homoerótica establecida" (Panesi, 1998, p. 44).

En este devenir teórico-crítico, el autor arriba a la conclusión de una tesis que plantea al inicio del trabajo: "la literatura habla de aquello que en la vida cultural se encuentra en proceso de invención" (1998, p. 42); o -agrego-, de lo que se vislumbra o está por suceder o emerger.

De este modo, se desenvuelve esa especie de metodología operacional recurrente entre las intervenciones críticas y las intervenciones didácticas de Jorge Panesi que se puede apreciar "a partir del ejercicio de la crítica literaria y de su enseñanza" (Gerbaudo, 2016, p. 260). 


\section{Ludmer: literatura y subalternidad}

Josefina Ludmer es una agente fundamental de la renovación teórica-crítica en el campo de los estudios literarios en Argentina. Profesora y crítica de notable agudeza, a cargo de la cátedra “Teoría Literaria II” desde 1986, el programa que examinamos en este trabajo es el último a su cargo. Cabe señalar que la asignatura nace de la transformación del Seminario "Algunos problemas de Teoría Literaria" dictado en 1985 junto con un grupo de jóvenes colaboradores que se habían formado con ella durante la última dictadura. Este Seminario -y la cátedra resultante- tiene especial relevancia en el campo de la enseñanza de la teoría y crítica literaria dado que se constituyó como "una de las usinas teóricas de la universidad argentina de la posdictadura, tanto por sus operaciones de importación como por las de invención y estímulo a la producción categorial desde una singular posición epistemológica" (Gerbaudo, 2016, p. 199).

Ludmer defendía la idea -innovadora y provocativa para esa época- de la transdisciplinariedad de las ciencias humanas como ciencias sociales y sostenía que la literatura, al insertarse en una esfera social, es indisociable de los fenómenos sociales, políticos y culturales (Gerbaudo, 2016).

Como punto de partida, es relevante mencionar que Ludmer estructura su esquema teórico-crítico sobre el concepto "modos de leer", armado a partir del concepto "modos de ver" de John Berger (Cfr. Gerbaudo 2016). Esta noción pone el acento en la 
lectura como producto de la tradición cultural (particularmente en el campo de la educación) ligado a una visión del mundo y apuesta a cuestionarla y cambiarla.

A partir de la década del noventa, nuevas inquietudes teóricas comienzan a tomar relieve en el campo. Así, las problematizaciones sobre las diferencias, las identidades, la heterogeneidad y la subalternidad (entre otras) comienzan a formar parte de sus propuestas (Bogado y Lacalle, 2017) y no casualmente una de las autoras que más se destaca en este eje es Gayatri Spivak. Es que "pareciera que el campo de la teoría literaria se está poniendo en cuestionamiento a sí mismo todo el tiempo" (Bogado y Lacalle, 2017, p. 6).

En este contexto, el surgimiento de debates y reflexiones en torno a algunos conceptos y las redefiniciones de otros instala interrogantes acerca de la interpretación y la construcción de sentidos, razón que fundamenta que el programa que analizamos lleve el título "La crisis de la teoría. Debates y redefiniciones". Consonantemente, estos nuevos planteos se trasladan a la dimensión didáctica.

En los objetivos se postula que el programa busca estudiar el desarrollo de nociones centrales de la teoría, interiorizarse de sus polémicas y transformaciones como así también analizar y discutir los nuevos conceptos y saberes (Ludmer, 1992). Coincidentemente, la sexta unidad plantea como eje estas transformaciones y renovaciones conceptuales, incorporando las últimas discusiones de la teoría y la crítica. El apartado enuncia: "La teoría hoy. Últimas cuestiones debatidas por la teoría y la crítica: la crítica feminista, las políticas de las diferencias, etc. 
Nuevos objetos, nuevos saberes y nuevas prácticas discursivas" (Ludmer, 1992, p. 1).

Claro que Ludmer ya había operado con estas categorías anteriormente. Siete años antes había publicado un breve ensayo en Puerto Rico titulado "Las tretas del débil" (1985), trabajo presentado en el Encuentro de escritoras latinoamericanas.

El trabajo hilvana un análisis novedoso de la "Respuesta a Sor Filotea" de Sor Juana Inés de la Cruz. Atenta siempre a las nuevas categorías que pujaban por instalarse en el campo "percibía que en las lecturas feministas, en las distribuciones jerárquicas del canon, en las colocaciones frente a discursos e instituciones había un campo a explorar" (Domínguez, 2017, p. 17).

La carta de Sor Juana que se analiza es una especie de relato autobiográfico de las prácticas de resistencia frente al poder, un espacio situado más allá de la diferencia de los sexos, donde el conocimiento constituye un acto de rebelión política (Ludmer, 1985). Desde allí, el ensayo explora el lugar de la mujer en una posición de subordinación y marginalidad, donde existe la simulación -la treta- de aceptación plena del lugar subalterno asignado socialmente.

Ludmer, que inventaba modelos teóricos y ponía en funcionamiento "máquinas de lectura" que articulaban literatura, política y cultura, en "Las tretas del débil" fundó una categoría que después sería fundamental para pensar la literatura argentina y latinoamericana: "voces subalternas". Particularmente señala:

Nos interesa especialmente el gesto del superior que consiste en dar la palabra al subalterno; hay en Latinoamérica una literatura propia, fundada en ese gesto. Desde la literatura 
gauchesca en adelante, pasando por el indigenismo y los diversos avatares del regionalismo, se trata del gesto ficticio de dar la palabra al definido por alguna carencia (sin tierra, sin escritura), de sacar a luz su lenguaje particular. Ese gesto proviene de la cultura superior y está a cargo del letrado, que disfraza y muda su voz en la ficción de la transcripción, para proponer al débil y subalterno una alianza contra el enemigo común. (Ludmer, 1985, p. 51).

La autora esgrime argumentos desde los postulados teóricos del poscolonialismo y la subalternidad para definir la posición del débil, del dominado (Gerbaudo, 2016). Sobre ese texto, su repercusión y alcances, Nora Domínguez expresa:

se instaló como modelo de lectura de las redes del poder y las estrategias de resistencia, impuso una categoría de análisis, demostró que ese juego de enunciaciones políticas podía extenderse hacia los usos de la voz de otros sujetos subalternos y no solo de las escritoras (Domínguez, 2017, p. 17).

Este "modo de leer" que Josefina Ludmer puso en funcionamiento incursionando por las lecturas feministas fue una de las operaciones críticas que posteriormente decantaron en los denominados "estudios de género" (Domínguez, 2017).

En este sentido, su construcción de las voces subalternas ha tenido reenvíos y derivas importantes en el campo de la teoría y crítica literaria argentina para elaborar abordajes desde perspectivas de género y queer. Tal es así que, por ejemplo, José Maristany (2016) se apropia de esta categoría para componer el ensayo "Usos de la voz subalterna: lesbianas y travestis en dos novelas argentinas", según en el cual la subalternidad proviene de la disidencia sexual y de género de los dos personajes analizados, una muchacha lesbiana y una travesti. 


\section{Umbrales de disrupción}

Por lo expuesto hasta aquí, al estar las perspectivas sexogenéricas constituidas por "formulaciones críticas con diferentes modulaciones y puntos de vista [...] que se ubican en disidencia respecto de la heterosexualidad obligatoria y normativa y el falogocentrismo" (Gasparri, 2016, p. 176), enfocada desde los puntos de vista antes enunciados, es admisible considerar que la nociones y derivas de las categorías teóricas enunciadas por estos estos agentes centrales de la crítica nacional pertenecen y nutren el grupo de esas formulaciones.

Estas perspectivas, al invocar el poder de la literatura para mirar la disidencia y dar lugar a conjeturas que hacen crujir la heteronorma cultural, también se puede afirmar que en los abordajes críticos de estas obras de la literatura argentina y latinoamericana -Nicolás Rosa pensando las relaciones entre literatura y sexualidad en El entenado de Juan José Saer, Jorge Panesi examinando las articulaciones entre homosexualidad y marginalidad en El juguete rabioso de Roberto Arlt y Josefina Ludmer descifrando las ligazones entre feminismo y subalternidad en la obra de Sor Juana-, y a partir del reuso de las categorías propuestas, se visualiza la proyección de operaciones teóricas en la enseñanza de la literatura del orden que sostenemos en la hipótesis inicial del trabajo, motivo por el cual estos procedimientos se convierten en umbrales de entrada o, como los designamos, "umbrales de disrupción". 
Así, denominamos "umbrales de disrupción" a las operaciones teóricas que constituyen las primeras aproximaciones críticas sobre las relaciones entre disidencias sexuales y literatura. Se configuran como dispositivos de composición transdisciplinar que trazan modos de leer para construir sentidos, objetos, saberes o conceptos que activen disensos, críticas e interrogantes para cuestionar el sistema heteronormativo cultural. Estos umbrales nutren y conforman la matriz genealógica de las perspectivas sexogenéricas en el campo de la literatura.

Las conexiones o vislumbres descriptos adquieren la potencialidad de ser asumidos como tales porque las perspectivas sexogenéricas apelan a operaciones conceptuales que muestran alianzas y contagios, contactos y articulaciones con la crítica de género y sexualidades (Gasparri, 2015). Y esos discursos conjugados y desplegados en el campo de la literatura "pueden dar lugar a una serie de conjeturas que articulan no sólo nociones vinculadas al desarrollo teórico de estas perspectivas sino sobre todo un espacio desconocido en términos de figuraciones corporales" (Gasparri, 2015, p. 3).

Estas coordenadas revelan en la relación entre literatura y perspectivas sexogenéricas, modos de lectura, intervenciones críticas y didácticas que permiten visibilizar que "las disidencias sexuales en la literatura, la crítica y la teoría literaria, y los estudios comparados, no son una novedad, sino que existen en el margen abyecto desde hace mucho tiempo" (Saxe, 2020, p. 9).

De este modo, los procedimientos teóricos observados, que emergen y se articulan en formulaciones de crítica literaria y 
propuestas didácticas, representan operaciones primigenias que vislumbraron lo que, posteriormente, fue dando paso a configuraciones teóricas más complejas en la constitución de las perspectivas sexogenéricas dentro de la agenda de los temas y problemas a abordar en el campo de los estudios literarios en la Universidad de Buenos Aires.

\section{Consideraciones finales}

En el recorrido teórico y analítico realizado examinamos algunas de las intervenciones críticas de Nicolás Rosa, Jorge Panesi y Josefina Ludmer poniéndolas en diálogo con las categorías y propuestas didácticas presentes en Seminarios de grado y Programas de cátedra que dictaron en la carrera de Letras de la Universidad de Buenos Aires durante la década del noventa.

A partir del corpus de materiales que hemos constituido, en tanto aproximación preliminar de "archivo sampleado operacional", pudimos detectar rastros de entramados transdisciplinares, préstamos, cruces y diálogos en los procedimientos presentes en las intervenciones críticas y las experiencias áulicas de Nicolás Rosa, Jorge Panesi y Josefina Ludmer. Esto nos permitió relevar operaciones teóricas que consideramos constituyen el umbral desde donde comenzaron a configurarse y consolidarse los estudios de perspectivas sexogenéricas en las carreras de Letras en la Universidad de Buenos Aires, procedimientos que explicamos a través de la construcción del concepto "umbrales de disrupción”. 
Cabe señalar que las reflexiones vertidas encuentran consistencia al ubicarse en el punto en que convergen las múltiples y plurales contribuciones que las nutren y atraviesan, y que coinciden en que, circunscritas a problemas de teoría y crítica literaria, las perspectivas sexogenéricas constituyen un cuerpo de conceptualizaciones en un heterogéneo marco transdisciplinar (García Canclini, 2010) cuyas nociones, articulaciones críticas y proyecciones pluridimensionales se configuran en la intersección de trayectorias amigas en un territorio mutante (Gasparri, 2015).

Finalmente, debemos destacar que la elaboración de aproximaciones que den cuenta de la emergencia y proyección de estas operaciones teóricas en los estudios literarios y en las prácticas de enseñanza de la literatura resultan de gran importancia. Por un lado, porque la observación de derivas teóricas que se ubiquen en este nicho -cuando no estaban del todo consolidadas, "sino más bien abiertas a las errancias críticocreativas" (flores, 2018, p. 155)- posibilita reconstruir genealogías críticas, culturales y lectoras muchas veces invisibilizadas sobre literatura y disidencia sexual (Saxe, 2020). Por otro, porque analizar estas intervenciones permite develar en el campo cultural nacional, miradas, procedimientos o producciones acerca de los cruces y articulaciones entre diferentes marcos teóricos que, a la vez, atraviesan y actúan sobre políticas culturales o educativas en relación con políticas sexuales (Flores, 2018; Saxe, 2018). 


\section{Referencias bibliográficas}

Arán, P. (2018). "Escribir desde el archivo". Pampa Arán y Diego Vigna. (Comp.) Archivos, artes y medios digitales. Teoría y práctica. Córdoba: Editorial CEA-UNC, 87-102.

Bermúdez Martínez, M. (2001). La incertidumbre de lo real: Bases de la narrativa de Juan José Saer. Oviedo: Universidad de Oviedo.

Blanco, A. (2006). Razón y modernidad. Gino Germani y la sociología en la Argentina. Buenos Aires: Siglo XXI.

Bogado, F. y Lacalle, J. M. (2017). “Aproximaciones a la historia de la Teoría Literaria en la carrera de Letras de la UBA Parte VII (1990-1999 bis)". Revista LUTHOR, 37, 1-19. http://revistaluthor.com.ar/spip.php?article194.

Bourdieu, P. (1999). Intelectuales, política y poder. Buenos Aires: Eudeba.

Buttler, J. (2014). "Beauvoir sobre Sade. La sexualidad como una ética”. ¿A quién le pertenece Kafka? Santiago de Chile: Polinodia, 109-135.

Córdoba, D. (2007). "Teoría queer: reflexiones sobre sexo, sexualidad e identidad. Hacia una politización de la sexualidad”. David Córdoba, Javier Sáez y Paco Vidarte (Eds.). Teoría Queer. Políticas Bolleras, Maricas, Trans, Mestizas. Barcelona: Egales, 21-66.

Dalmaroni, M. (2010). "La obra y el resto. Literatura y modos del archivo". Telar, 7 (8), UNT, 9-30.

Domínguez, N. (2017). "Unas páginas para Josefina Ludmer". Zama, 9, 17-19.

flores, v. (2018). "Esporas de indisciplina. Pedagogías trastornadas y metodologías queer". VVAA. Pedagogías Transgresoras II. Sauce Viejo: Bocavulvaria Ediciones, 139208. 
Foster, H. (2017). “Un impulso (an)archivístico”. Mónica Bernabé (Comp.). En el borde del mundo. Vanguardias de archivo en América Latina. Rosario: HyA Ediciones, pp. 163-196.

Foucault, M. (1970). La arqueología del saber. Buenos Aires: Siglo XXI.

Frappier- Mazur, L. (2006). Sade y la escritura de la orgía. Buenos Aires: Artes del Sur.

García Canclini, N. (2010). La sociedad sin relato. Antropología y estética de la inminencia. Buenos Aires: Katz Editores.

Gasparri, J. (2015). "Notas acerca de lo queer en la crítica literaria argentina”. Actas IX Congreso Internacional Orbis Tertius de Teoría y Crítica Literaria. Universidad Nacional de La Plata. http://www.memoria.fahce.unlp.edu.ar/trab eventos/ev.864 8/ev.8648.pdf.

---. (2016). Presentación del Dossier "Perspectivas sexogenéricas. Literatura, arte y política”. Badebec, 6 (11), 174-183. https://revista.badebec.org/index.php/badebec/article/view/ 185 .

Gerbaudo, A. (2016). Políticas de exhumación. Las clases de los críticos en la universidad argentina de la posdictadura (19841986). Santa Fe: Ediciones UNL.

Hidalgo Nácher, M. (2017). "Imaginación crítica de Nicolás Rosa”. El taco en la brea, 4 (5), 39-68.

Lacalle, J. M. y Bogado, F. (2017). "Aproximaciones a la historia de la Teoría Literaria en la carrera de Letras de la UBA Parte VII (1990-1999)". Revista LUTHOR, 33, 1-21. http://revistaluthor.com.ar/spip.php?article194.

Ludmer, J. (1985). "Las tretas del débil”. Patricia González y Eliana Ortega (Eds.) La sartén por el mango. Encuentro de escritoras latinoamericanas. Puerto Rico: El Huracán, 47-54.

Maradei, G. (2020). "Suely Rolnik y Nelly Richard: Productivizaciones con perspectiva de género de la teoría 
postestructuralista en América Latina”. Landa, 8 (2), 235-246. https://repositorio.ufsc.br/bitstream/handle/123456789/209 094/14\%20Suely\%20Rolnik\%20y\%20Nelly\%20Richard\%20p or\%20Guadalupe\%20Maradei.pdf?sequence $=1$ \&isAllowed $=\mathrm{y}$

Maristany, J. (2016). "Usos de la voz subalterna: lesbianas y travestis en dos novelas argentinas". Chasqui, 45 (1), 16-129. www.jstor.org/stable/24810881

Mattio, E. (2012). "¿De qué hablamos cuando hablamos de género? Una introducción conceptual”. AAVV, Sexualidades, desigualdades y derechos. Córdoba: Ciencia, Derecho y Sociedad Editorial.

Mendoza, J. J. (2019, 16 de septiembre). "La Argentina, floja de papeles: por qué es tan difícil conservar nuestros archivos". P. Conde. Clarín. https://www.clarin.com/cultura/juan-josemendoza-importancia-preservar-archivosnacionales o rroqwjYCe.html

Rosa, N. (1990). "Una enfermedad del sentido. La construcción neológica en el discurso delirante”. Revista de Letras, 2, 22-25.

---. (1994). “Cárcel de amor”. Revista de Letras, 3, 95-98.

---. (1999). "CUERPO/ CUERPOS. Hacia una gramática social de los cuerpos”. Revista de Letras, 6, 5-14.

---. (2002). “De monstruos y pasiones”. Materia, 2, 205-222.

Rubin, G. (1986). "El tráfico de mujeres: notas sobre la "economía política" del sexo”. Nueva Antropología, 8 (30), 95-145.

Saxe, F. (2018). "La trampa mortal: derivas maricas de la disidencia sexual en la producción de conocimiento científico al recuerdo infantil de un beso”. Etcétera. Revista del Área de Ciencias Sociales del CIFFyH, 3, Córdoba: UNC, 1-26.

---. (2020). "Literaturas y disidencias sexuales: sub-versiones, disturbios, genealogías". Descentrada, 4 (2). https://doi.org/10.24215/25457284e114 
Spivak, G. (1998). “¿Puede hablar el sujeto subalterno?”. Orbis Tertius, 3 https://www.orbistertius.unlp.edu.ar/article/view/OTvo3no6 to1/pdf 240. Trad. J. Amícola.

Zorrilla Sirlín, N. (2016). "Sade en el pensamiento feminista". Asparkía, 29, 91-108.

\section{Documentos}

Ludmer, J. (1992). Programa de cátedra "Teoría Literaria II" (1 ${ }^{\circ}$ cuatrimestre). Departamento de Letras. FFyL-UBA.

Panesi, J. (1993). Programa de cátedra "Teoría y Análisis Literario - Cátedra C". ( $1^{\circ}$ cuatrimestre). Departamento de Letras. FFyL-UBA.

Rosa, N. (1985). Programa del Seminario "Análisis textual de El entenado de J.J. Saer”. ( $2^{\circ}$ cuatrimestre). Departamento de Letras. FFyL-UBA.

---. (1990). Programa de cátedra "Teoría Literaria III" (2 cuatrimestre). Departamento de Letras. FFyL-UBA.

Fecha de recepción: 10/05/2021

Fecha de aprobación: 10/06/2021 